\title{
Luteinizing Hormone-Releasing Hormone in the Vomeronasal System and Terminal Nerve of the Hamster $^{a}$
}

\author{
MICHAEL N. LEHMAN, ${ }^{b}$ SARAH W. NEWMAN, ${ }^{c}$ AND \\ ANN-JUDITH SILVERMAN ${ }^{d}$ \\ ${ }^{b}$ Department of Anatomy and Cell Biology \\ University of Cincinnati College of Medicine \\ Cincinnati, Ohio 45267 \\ ${ }^{c}$ Departments of Anatomy and Cell Biology, Medical Science II \\ University of Michigan \\ Ann Arbor, Michigan 48109 \\ ${ }^{d}$ Departments of Anatomy and Cell Biology \\ Columbia University College of Physicians \& Surgeons \\ New York, New York 10032
}

The vomeronasal system of mammals is a specialized chemosensory pathway that parallels the main olfactory system but is anatomically distinct from its peripheral aspect through its projections into the central nervous system. ${ }^{1,2}$ Recent evidence suggests a predominant role for the vomeronasal system in conveying the influence of odor stimuli upon neuroendocrine events ${ }^{3-5}$ and on a variety of motivated behaviors, including sex, ${ }^{6}$ aggression, ${ }^{7}$ and maternal behavior. ${ }^{8}$ This functional role probably reflects the relatively direct projections of this chemosensory system to areas of the ventral forebrain important in the control of neuroendocrine and behavioral events. The sole central target of the vomeronasal organ is the accessory olfactory bulb (AOB), neurons which in turn project to several nuclei of the medial amygdala. ${ }^{1.9}$ In particular, the medial nucleus of the amygdala $(\mathbf{M})$, has projections to the preoptic area and hypothalamus, and has been strongly implicated in mediating the influence of odor cues upon the neuroendocrine system and behavior. ${ }^{10.11}$

Axons containing immunoreactive luteinizing hormone-releasing hormone (LHRH) are found throughout the vomeronasal system in the rat and hamster. ${ }^{12-14}$ Sparse LHRH fibers are seen within the neuroepithelium of the vomeronasal organ itself. ${ }^{12.15}$ LHRH fibers and cells, defined as a subset of the terminal nerve, ${ }^{15,16}$ are present in close proximity to the vomeronasal nerve in the nasal cavity. Centrally, a dense plexus of LHRH fibers innervates the glomerular layer of the AOB, the site of the first synapse in this sensory system. Occasionally, isolated LHRH perikarya are found within the AOB as well. Further caudally, LHRH fibers are seen adjacent to the optic tract within the superficial plexiform layer of $\mathbf{M}$, that layer which receives

\footnotetext{
${ }^{a}$ This work was supported by NIH Grants HD 21968, HD 10665 and NS 20629
} 
afferent chemosensory information from the AOB. This LHRH innervation of the central targets of the vomeronasal system is in contrast to their relatively sparse presence in central targets of the olfactory system. Evidence that immunoreactive LHRH axons establish synaptic contacts in the AOB, ${ }^{17}$ and that the LHRH content of this area increases during odor exposure, ${ }^{18}$ have led to the suggestion that LHRH neurons and their fibers may directly modulate the processing of vomeronasal sensory information. Since a major neurosecretory role of LHRH neurons is in the control of gonadotropin secretion by way of projections to the median eminence (ME), LHRH input to both neurohemal and chemosensory targets may serve to coordinate neuroendocrine and behavioral aspects of reproduction.

Although the distribution of LHRH cells and fibers in the mammalian brain has been well characterized, ${ }^{13.19-21}$ the precise origin of LHRH input to the vomeronasal system, as well as to other brain areas, remains unclear. In part, the reason for this has been that LHRH neurons are not clustered within a single nucleus or brain area, but are relatively widely scattered throughout the forebrain. In the hamster, for example, a subset of immunoreactive LHRH cells are present within the terminal ganglion, in its peripheral, intracranial, and intracerebral portions. ${ }^{15}$ Scattered LHRH cells are also located in the medial portion of the anterior olfactory nucleus, the anterior hippocampal rudiment, and the indusium griseum. As mentioned, single isolated LHRH cells are sometimes found within the AOB itself. However, the vast majority of these cells in the hamster and other species are found in a continuum that extends from the diagonal band and medial septum to the preoptic area and anterior hypothalamus. ${ }^{13,19,21}$ In the rat, LHRH cells which project to the ME are evenly distributed throughout these areas; within either the diagonal band, medial septum, or preoptic area, cells projecting to the ME account for about half of all LHRH neurons. ${ }^{22}$ It is not known whether those LHRH cells, which do not project to the $\mathrm{ME}$, innervate neural targets instead. Similarly, the possible central targets of LHRH cells in the terminal ganglion are not clear, although a recent study, ${ }^{23}$ using immunocytochemistry after knife cuts, suggests that the peripheral portion of the terminal nerve in the hamster projects centripetally.

In order to determine which LHRH cells project to the central targets of the vomeronasal system in the hamster, we employed a combination of retrograde tracttracing techniques, using fluorescent tracers, with immunocytochemistry. To assess the possibility that single LHRH cells influence both neuroendocrine and chemosensory function, we first determined the location of LHRH cells which project to the ME and compared their distribution with that of cells projecting to the $A O B$ and $M$. Finally, we determined the distribution of LHRH cells which project to the lateral septum (LS), to test the possibility suggested by the literature ${ }^{24.25}$ that this area receives central input from LHRH cells of the terminal ganglion.

Adult male golden hamsters (120 gm; Harlan Industries, Inc.) were anesthetized with sodium pentobarbital $(75 \mathrm{mg} / \mathrm{kg}$ ) and received unilateral stereotaxic injections of fluorescent tracers directed toward either the ME, M, or LS, using a microinjection device (Kopf Instruments) which held a 1- $\mu$ l Hamilton syringe. Two fluorescent tracers were used in this study; individual animals received 50-100 $\mathrm{nl}$ injections of either $4 \%$ Fluoro-Gold ${ }^{26}$ (Fluorochrome, Inc.) in $0.9 \%$ saline, or a $10 \%$ solution of rhodamine-coated latex microspheres ${ }^{27}$ (Tracer Technologies) in the same vehicle. Several animals received tracer injections directed toward the third and lateral ventricles as a control, since injections into the $\mathrm{ME}, \mathbf{M}$, and LS often spread into these ventricles.

After a postsurgery survival of three to five days, animals were anesthetized with pentobarbital and perfused intracardially with $50-100 \mathrm{ml}$ of $0.9 \%$ saline solution 
followed by $300-500 \mathrm{ml}$ of Zamboni's fixative (1.8\% paraformaldehyde, $2 \%$ picric acid in $0.1 \mathrm{M}$ phosphate buffer, $\mathrm{pH} 7.3$ ). Brains were carefully removed with meninges intact, postfixed in the same fixative for 6-24 hr, and embedded in the egg yolk-gelatin matrix. After infiltration with $20 \%$ sucrose in the same fixative, coronal sections ( 50 $\mu \mathrm{m}$ ) were cut on a freezing microtome. Sections were washed overnight in $0.1 \mathrm{M}$.

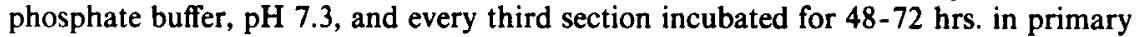
antiserum against LHRH (LR-1 generously provided by Dr. R. Benoit). Sections were subsequently processed for immunocytochemistry using an avidin-fluorescein procedure (Vectastain, Vector Laboratories), mounted and coverslipped with glycerol in phosphate buffer. Sections were examined and photographed using a Nikon Microphot FX equipped for fluorescent microscopy with fluorescein, rhodamine, and ultraviolet (UV) excitation filters.

The morphology and distribution of immunofluorescent LHRH cells and fibers seen in these animals was identical to that described previously for this species using immunoperoxidase methods. ${ }^{13,14}$ Immunoreactive neurons appeared as either bipolar or unipolar cells, similar to those described in most other mammals. ${ }^{19,20}$ LHRH fibers were most often seen as beaded varicosities, with the notable exception of fibers within the terminal nerve and ganglion which had a flat, ribbon-like appearance. As in earlier studies, immunoreactive LHRH cells were found scattered over a wide area of the ventral forebrain, ranging from the olfactory peduncle, rostrally, to the anterior hypothalamus, caudally (see FIGURE 3). Clusters of LHRH cells were identified as the intracerebral portion of the terminal ganglion by their association with fibers of the terminal nerve, at the level of the anterior hippocampal rudiment. A few scattered immunoreactive cells were seen in the anterior hippocampal rudiment itself, as well as in the indusium griseum, and more rostrally in the medial portion of the anterior olfactory nucleus and within the AOB. The majority of LHRH perikarya were found scattered in a diffuse continuum that includes cells in the diagonal band, medial septum, preoptic area, and anterior hypothalamus. Like the rat, ${ }^{19}$ but unlike the guinea pig ${ }^{20}$ and monkey, ${ }^{28}$ LHRH cells in the hamster were not found within the medial basal hypothalamus. LHRH fibers with beaded varicosities, as expected, were seen within several neurohemal regions, such as the $\mathrm{ME}$, the organum vasculosum of the lamina terminalis (OVLT), and the subfornical organ. Additionally, LHRH fibers were also found within presumptive neural targets, including the glomerular layer of the AOB, the superficial plexiform layer of $M$, and the LS.

In these same animals both Fluoro-Gold and rhodamine-coated microspheres (hereafter termed "rhodabeads") proved to be sensitive and easily discernible markers of retrogradely labeled neurons. Under UV illumination retrogradely transported Fluoro-Gold appeared to be sequestered in bright yellow granules, presumably lysosomes, within cell bodies and dendrites. Similarly, observed with a rhodamine filter, rhodabeads appeared as bright red beads within the outlines of cell bodies and dendrites. Neither tracer appreciably labeled axons at a distance from the injection site, although Fluoro-Gold occasionally labeled fibers that could be followed from intensely labeled cells at or near the injection site. The overall pattern of retrograde labeling following an injection in a given site, was the same regardless of the tracer used.

Microinjections of either Fluoro-Gold or rhodabeads in eighteen animals were successfully centered within either the $\mathrm{ME}(n=5)$, AOB $(n=5), \mathrm{M}(n=5)$, or LS $(n=3)$. Representative injections into three of these sites, the ME, AOB, and $M$, are shown in FIGURE 1. The size of an effective injection site was defined as that area around the needle tract where fluorescent dye or beads completely filled the neuropil, intensely labeling all cells and fibers. All injection sites used for histological analysis overlapped the extent of immunoreactive LHRH fibers in that brain region. 

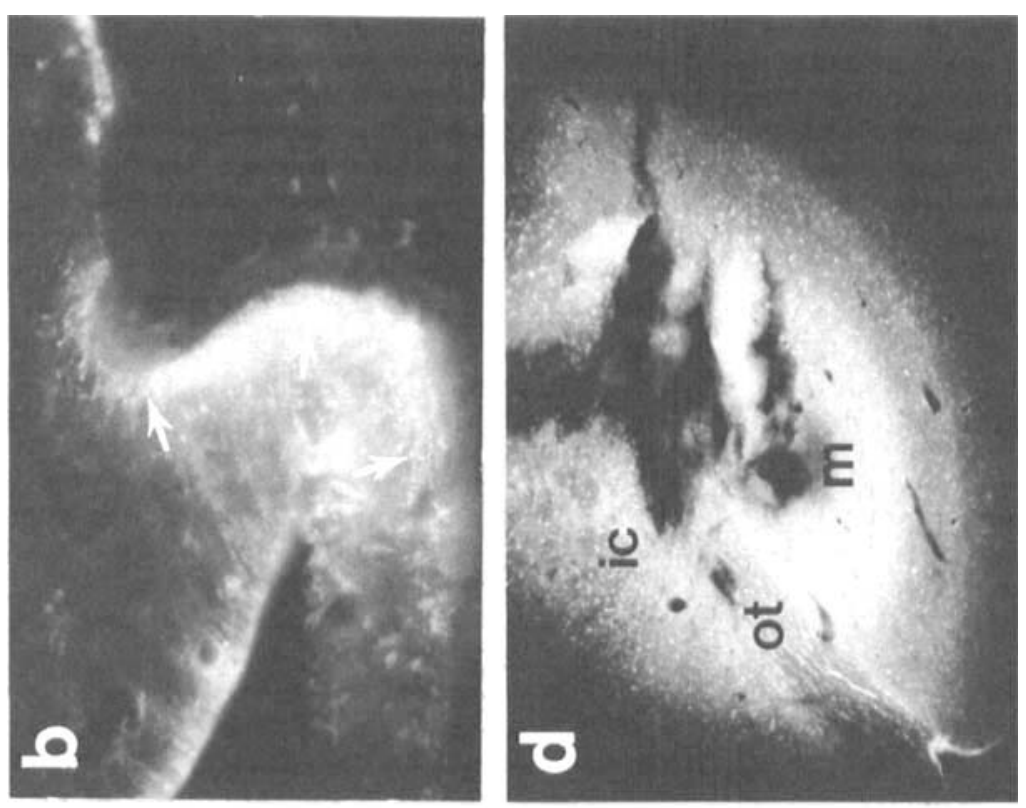

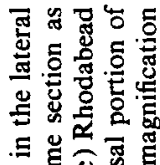

토을 运造焉 5。

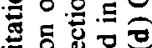
을

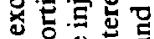
>吕焉 สว

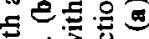
家家的 过是 응뭉

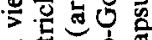
둥ㅇㅇ 范骂骂

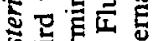

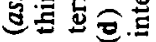
돌 몽

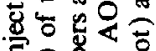

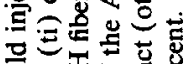
응 녕

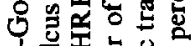

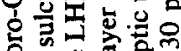

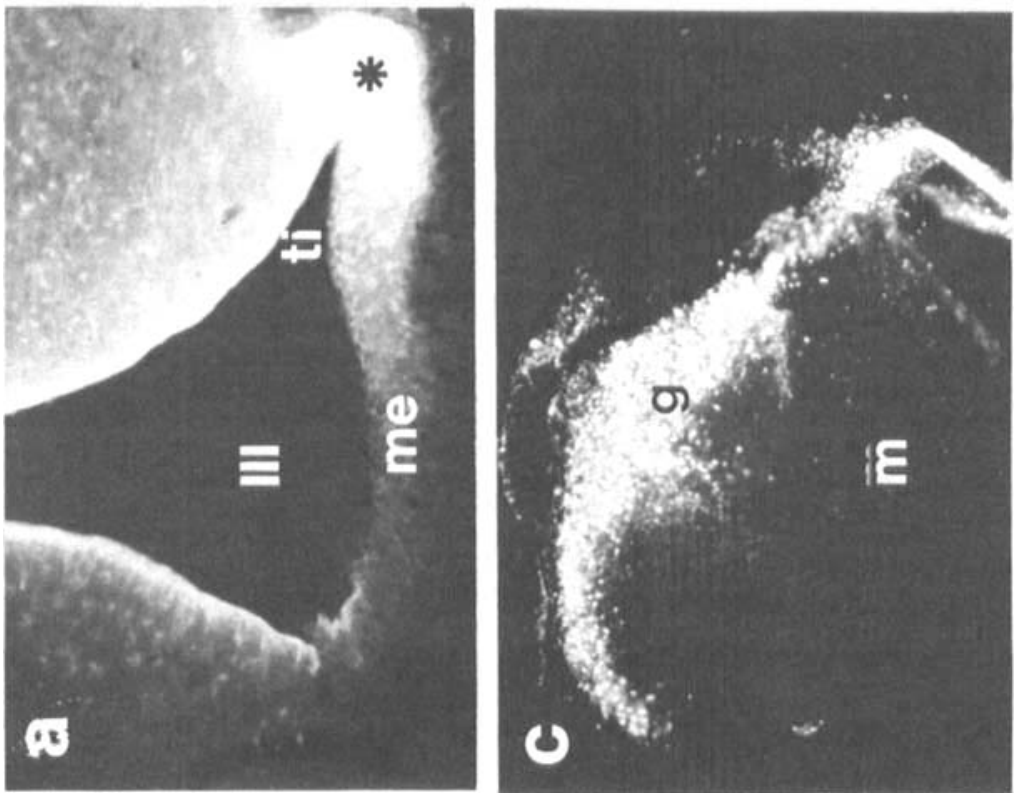
品

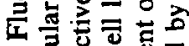

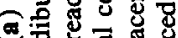

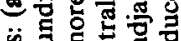

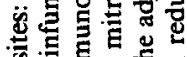
कó 岁它的

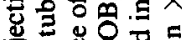

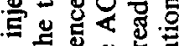

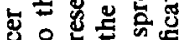

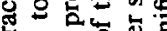

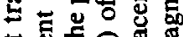

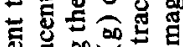
舫

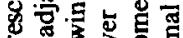
守蛋员豆 密它它

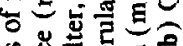
을 현 영 월. 5 品的 它究 5 5

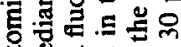
总记完

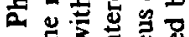
- 5 吉远

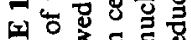

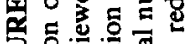
궁을 영

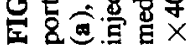


In most animals, verification of this overlap was obtained by direct examination of those sections for immunoreactive LHRH fibers. By switching between fluorescent filters, the presence of fluorescein-labeled LHRH fibers within each Fluoro-Gold or rhodabead injection was confirmed. Injections in the ME, for example, were centered in its lateral portion adjacent to the tubero-infundibular sulcus of the third ventricle, the area of densest LHRH fibers and terminals (FIG. 1B). In the AOB, tracer injections involved that structure's glomerular layer (FIG. 1C); in the amygdala, injections were centered in the dorsal part of the medial nucleus adjacent to the optic tract, although in some cases there was spread of fluorescent tracer into the optic tract and internal capsule (FIG. 1D). Tracer injections in the LS (see FIGURE 7) overlapped the location of beaded LHRH fibers in that area which ramify close to the lateral ventricle.

Retrogradely labeled LHRH cells were easily identified in these brains. Immunoreactive LHRH perikarya, labeled green with avidin-fluorescein, when retrogradely labeled also contained bright yellow (Fluoro-Gold) or red (rhodabeads) granules in their cell bodies and dendrites (FIGS. 2A-C). For each animal, the location of both labeled and unlabeled LHRH neurons were plotted onto a series of standard coronal sections through the hamster brain (FIGS. 3-6). In each animal, observations of the location of retrogradely labeled non-LHRH cells provided additional verification of the effective locus of the injection site. For example, tracer injections into the ME consistently labeled cells in the paraventricular and arcuate nuclei of the hypothalamus, both of which are known sources of afferent input to the ME. ${ }^{29}$ Following AOB injections, cells were labeled in the bed nucleus of the accessory olfactory tract, as well as in $M{ }^{30}$ In the case of $\mathbf{M}$ injections, labeled non-LHRH cells were seen in the AOB, bed nucleus of the stria terminalis and ventromedial hypothalamus. ${ }^{31} \mathrm{LS}$ injections labeled cells in the hippocampal formation. ${ }^{32}$ Control injections of tracer into the third or lateral ventricle failed to label any neurons.

Following tracer injections into the ME, retrogradely labeled LHRH neurons were found scattered throughout the diagonal band, medial septum, preoptic area, and anterior hypothalamus (FIG. 2A; FIG. 3 ). In addition, a small number of retrogradely labeled LHRH cells were seen in the intracerebral portion of the terminal ganglion and in the adjacent anterior hippocampal rudiment (FIG. 2B; Fig. 3). In all these areas, labeled LHRH neurons tended to be located ipsilateral to the injection site. At any level, LHRH cells which project to the ME accounted for about half of all immunoreactive LHRH cells in areas ipsilateral to the injection. Retrogradely labeled LHRH cells were often seen in close proximity to unlabeled LHRH neurons (FIG. 2A). As noted above labeled non-LHRH cells were seen in several sites of origin of known afferents to the $\mathrm{ME}$, including the paraventricular and arcuate nuclei of the hypothalamus.

In contrast to the pattern of labeling following $\mathrm{ME}$ injections, tracer injections into the AOB consistently labeled only one or two LHRH neurons. Labeled LHRH cells were located in the superficial plexiform layer of the medial division of the anterior olfactory nucleus ipsilateral to the injection site (FIG. 4). This sparse pattern of LHRH cell labeling was evident though the same injections produced intense retrograde labeling of non-LHRH cells at more distant sites, including the bed nucleus of the accessory olfactory tract and $M$. The overall distribution of immunoreactive LHRH neurons in animals bearing AOB injections, as well as in hamsters with $M$ and LS injections, was essentially the same as that seen in animals with ME injections (compare FIgURES 3 and 4).

Tracer injections into the medial amygdala, like those into the $\mathrm{AOB}$, labeled only one or two LHRH neurons in each brain, usually ipsilateral to the injection site (FIG. 2C; FIG. 5). LHRH cells projecting to $M$ were located in the ventromedial preoptic area at the level of the OVLT (FIG. 2C; FIG. 5). Despite the sparse labeling of LHRH 

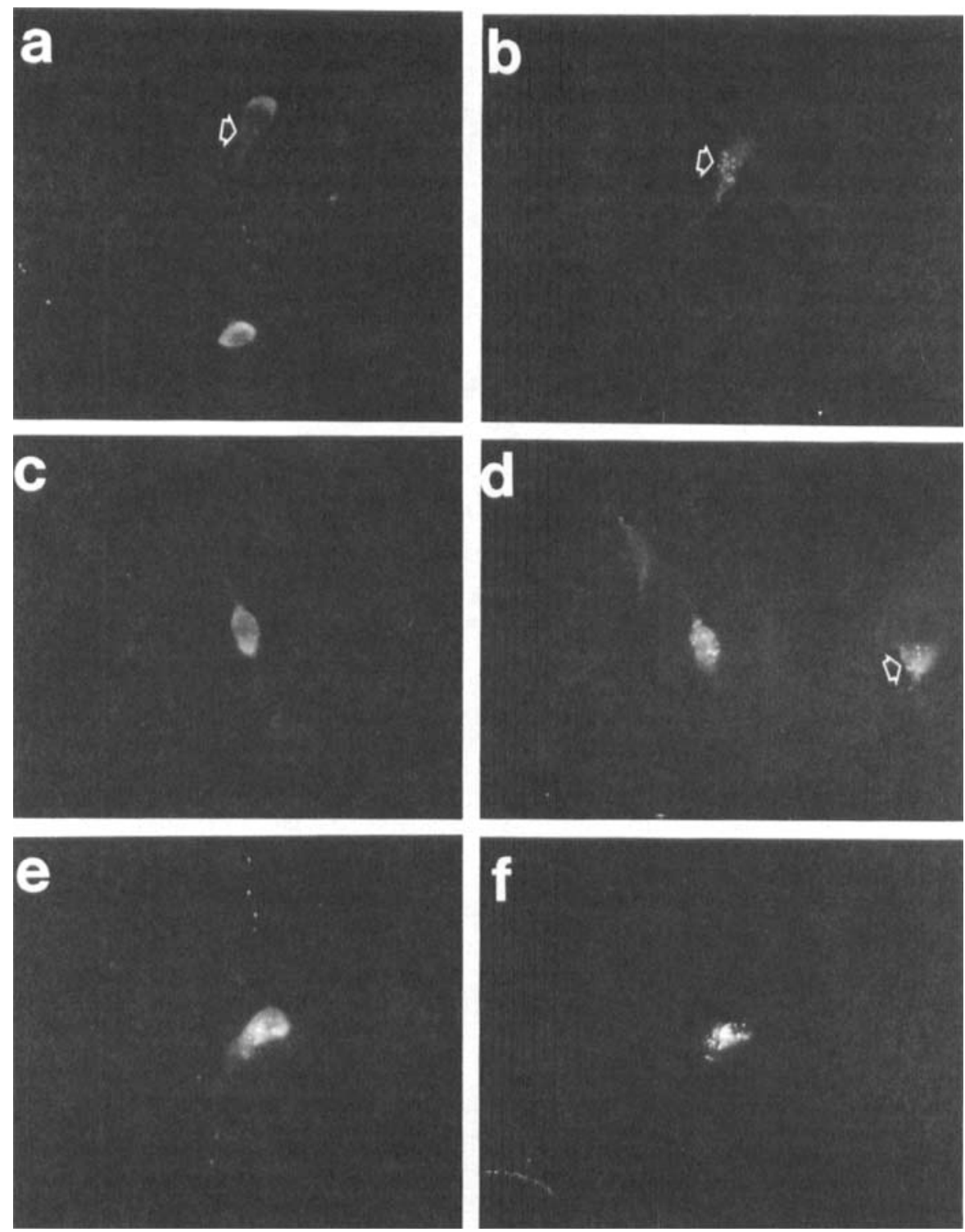

FIGURE 2. Retrogradely labeled LHRH neurons. (a) two LHRH cells in the medial septum labeled with fluorescein; (b) the same field as (a) viewed with a UV excitation showing that one of these cells (arrow) is retrogradely labeled with granules of Fluoro-Gold following an injection into the median eminence; (c) LHRH cell in the anterior hippocampal rudiment viewed with a fluorescein filter; (d) under a UV filter the same cell in (c) is seen to be retrogradely labeled with Fluoro-Gold following an injection into the median eminence. Note adjacent retrogradely labeled non-immunoreactive cell (arrow); (e) LHRH cell in the preoptic area; (f) the same cell in (e) under a rhodamine filter appears retrogradely labeled with rhodabeads (arrow) following an injection into the medial nucleus of the amygdala. Rhodabeads are also visible, though not as intense, under a fluorescein filter (e). 
cells, the same injections labeled non-LHRH cells at sites consistent with an earlier tract tracing study, ${ }^{31}$ including the $\mathrm{AOB}$, the bed nucleus of the stria terminalis, and the ventromedial hypothalamic nucleus.

Following tracer injections into the LS, retrogradely labeled LHRH cells were found primarily in the rostral medial septum ipsilateral to the injection (level not shown in FIG. 6). Notably, a few LHRH cells in the intracerebral portion of the terminal ganglion and anterior hippocampal rudiment were also retrogradely labeled.
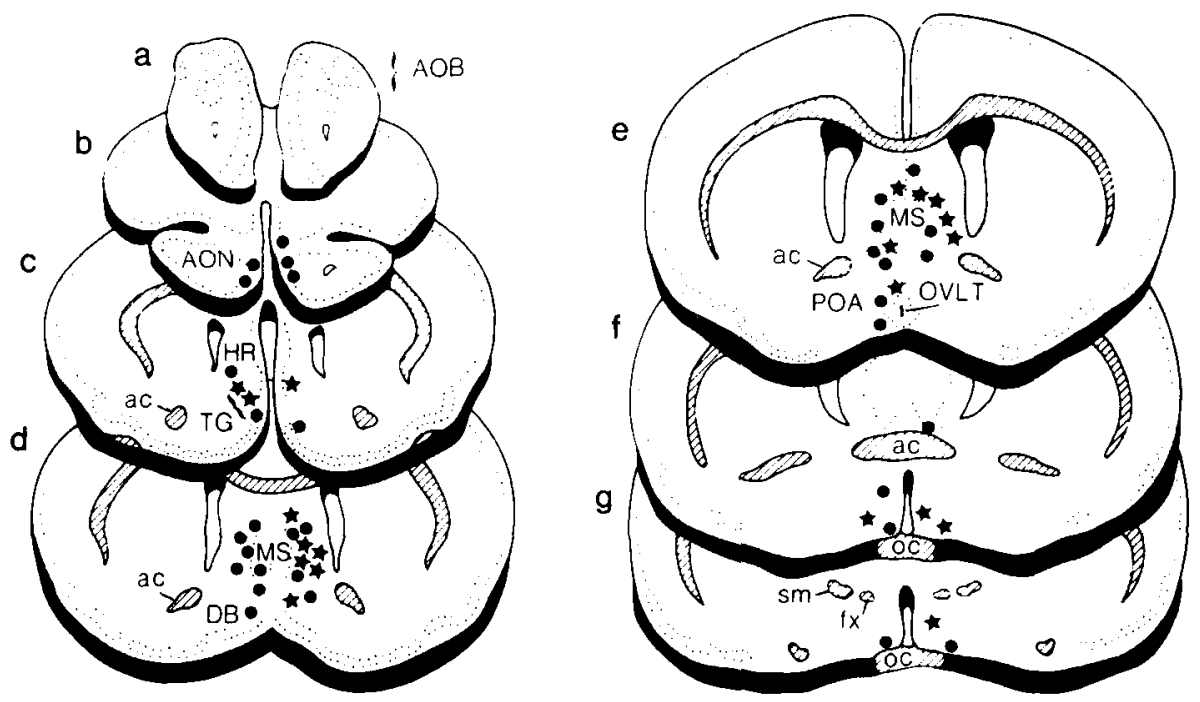

ME INJECTION

(H 11)

FIGURE 3. Drawings of coronal brain sections, rostral to caudal (a-g), upon which are plotted the location of immunoreactive LHRH cells (solid circles), including those that were retrogradely labeled (stars), in a hamster that received an injection of Fluoro-Gold into the left median eminence (ME) (see FigURE 1A). Abbreviations: AOB, accessory olfactory bulb; AON, anterior olfactory nucleus; HR, anterior hippocampal rudiment; $T G$, terminal ganglion, intracerebral portion; ac, anterior commissure; DB, diagonal band, MS, medial septum; OLVT, organum vasculosum of the lamina terminalis; POA, preoptic area; oc, optic chiasm; sm, stria medullares; fx, fornix.

Interestingly, septal LHRH neurons situated in close proximity to the injection site were always unlabeled, even though the neuropil surrounding them was often intensely fluorescent. LS injections routinely labeled neurons in the hippocampal formation, a finding consistent with earlier studies. ${ }^{32}$

A schematic summary of the location of LHRH cells which project to either the $\mathrm{AOB}, \mathrm{M}$, or ME is illustrated in FigurE 8. On the basis of these findings it seems unlikely that LHRH input to the vomeronasal system arises from any single group of LHRH cells. LHRH neurons which project to the AOB are, in part, located in 

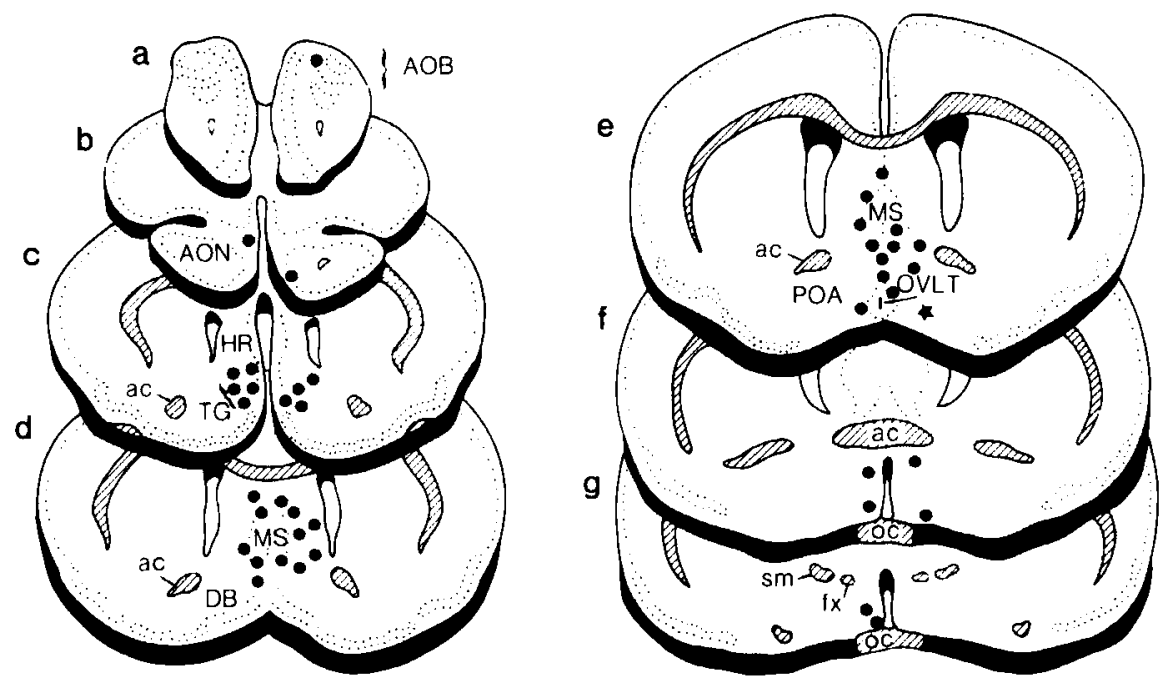

\section{MA INJECTION (Hi5)}

FIGURE 4. Drawings of coronal brain sections, rostral to caudal $(\mathrm{a}-\mathrm{g})$, depicting the location of LHRH cells (solid circles), including one which was retrogradely labeled (stars) in an animal which received an injection of Fluoro-Gold in the medial nucleus of the amygdala (MA) on the left side of the brain (see Figure 1B). Abbreviations same as Figure 3.
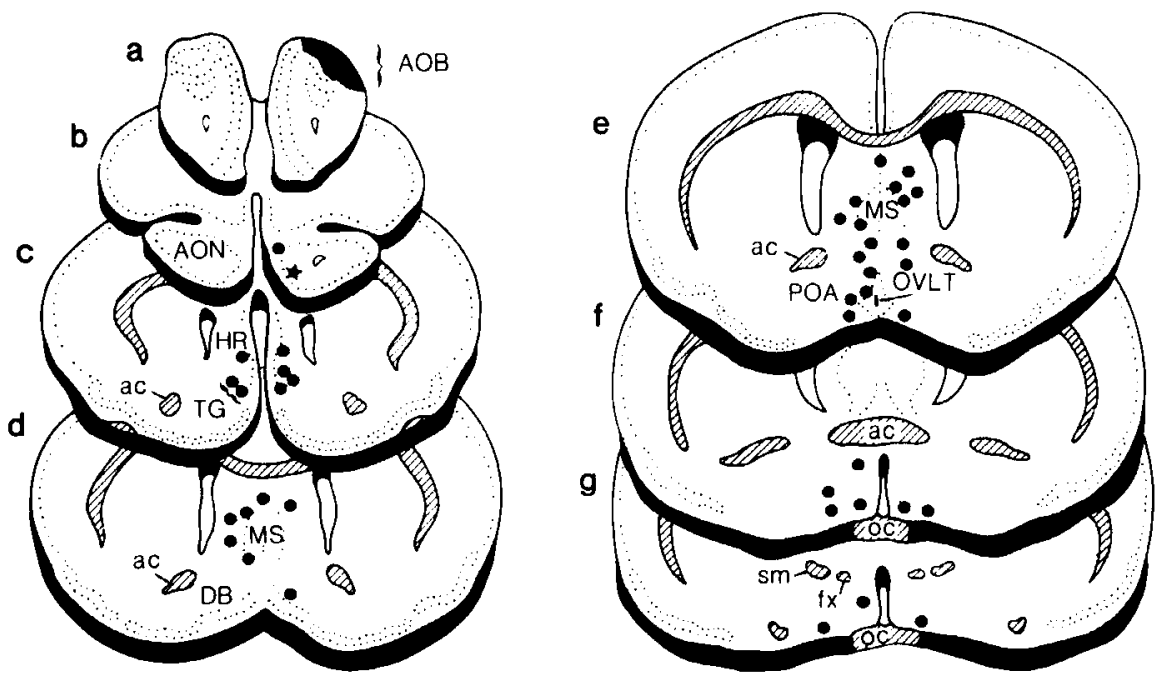

\section{AOB INJECTION}

(H 8)

FIGURE 5. Drawing of coronal brain sections, rostral to caudal (a-g), depicting the location of LHRH cells (solid circles), including one which was retrogradely labeled (stars) following an injection of Fluoro-Gold into the left accessory olfactory bulb (AOB) (shaded area). Abbreviations same as Figure 3. 
the medial olfactory peduncle, although the extreme paucity of these cells compared to the dense LHRH fiber plexus in the AOB suggests either (1) that axons of these neurons ramify extensively upon entering the $A O B$, or (2) that additional cells of origin to these fibers are located outside the central nervous system, perhaps in the peripheral portion of the terminal nerve. Recent evidence ${ }^{23}$ indicating that the terminal nerve in the hamster carries afferent fibers to the brain support the latter possibility. In addition, we have noted that even following extensive unilateral or bilateral lesions of the intracerebral portion of the terminal nerve, LHRH fiber staining in the AOB remains comparable to that of intact brains (FIG. 7). We have not as yet examined the nasal cavities of hamsters with tracer injections into the AOB in order to see
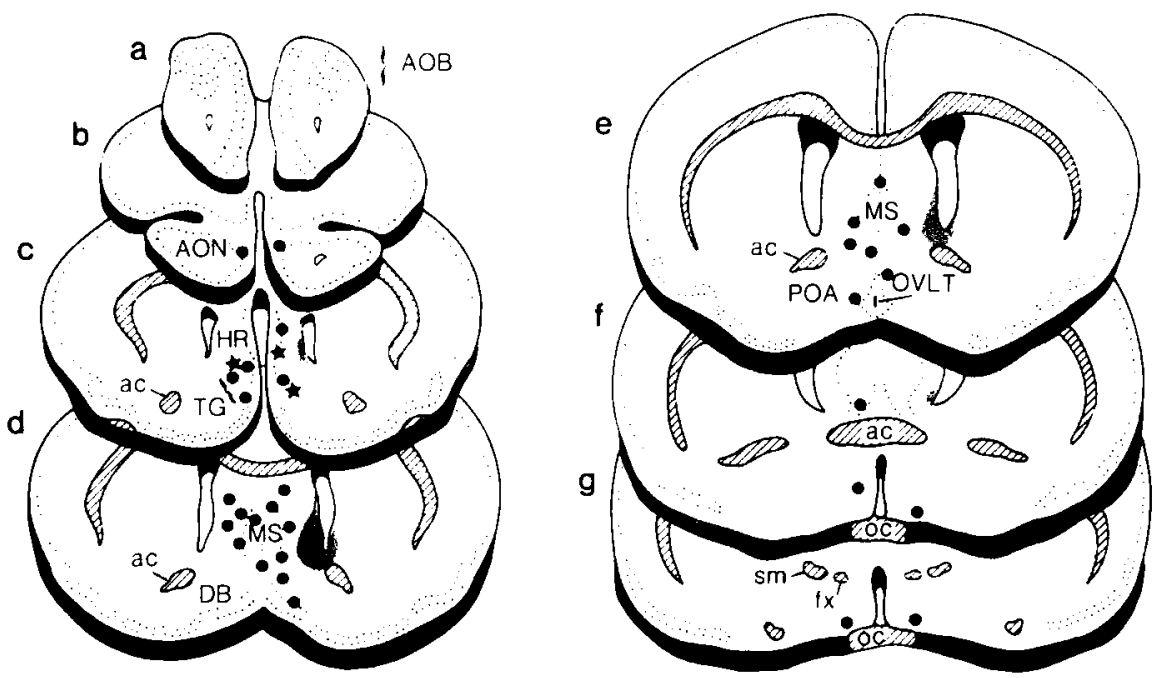

\section{LS INJECTION}

(H 14)

FIGURE 6. Drawing of coronal brain sections, rostral to caudal (a-g), depicting the location of LHRH cells (solid circles) and those which were retrogradely labeled (stars) following an injection of Fluoro-Gold (shaded area) into the left lateral septum (LS). All other abbreviations same as Figure 3.

whether LHRH cells associated with the peripheral portion of the terminal nerve may be retrogradely labeled.

LHRH cells which project to $M$ were found in the ventral preoptic area at the level of the organum vasculosum of the lamina terminalis, a region identified previously as a source of afferent input to $\mathbf{M} .^{27}$ These $\mathbf{L H R H}$ cells probably project to the amygdala by way of the stria terminalis, since numerous LHRH fibers are seen within this fiber bundle. ${ }^{13}$ The modest number of LHRH fibers normally seen in the superficial plexiform layer of $M$ is consistent with the small number of retrogradely labeled LHRH cells seen after amygdaloid injections. The possibility that LHRH cells in the preoptic area which project to $M$ also send processes to the $M E$ needs to be tested directly with multiple tracer injections into a single animal. 

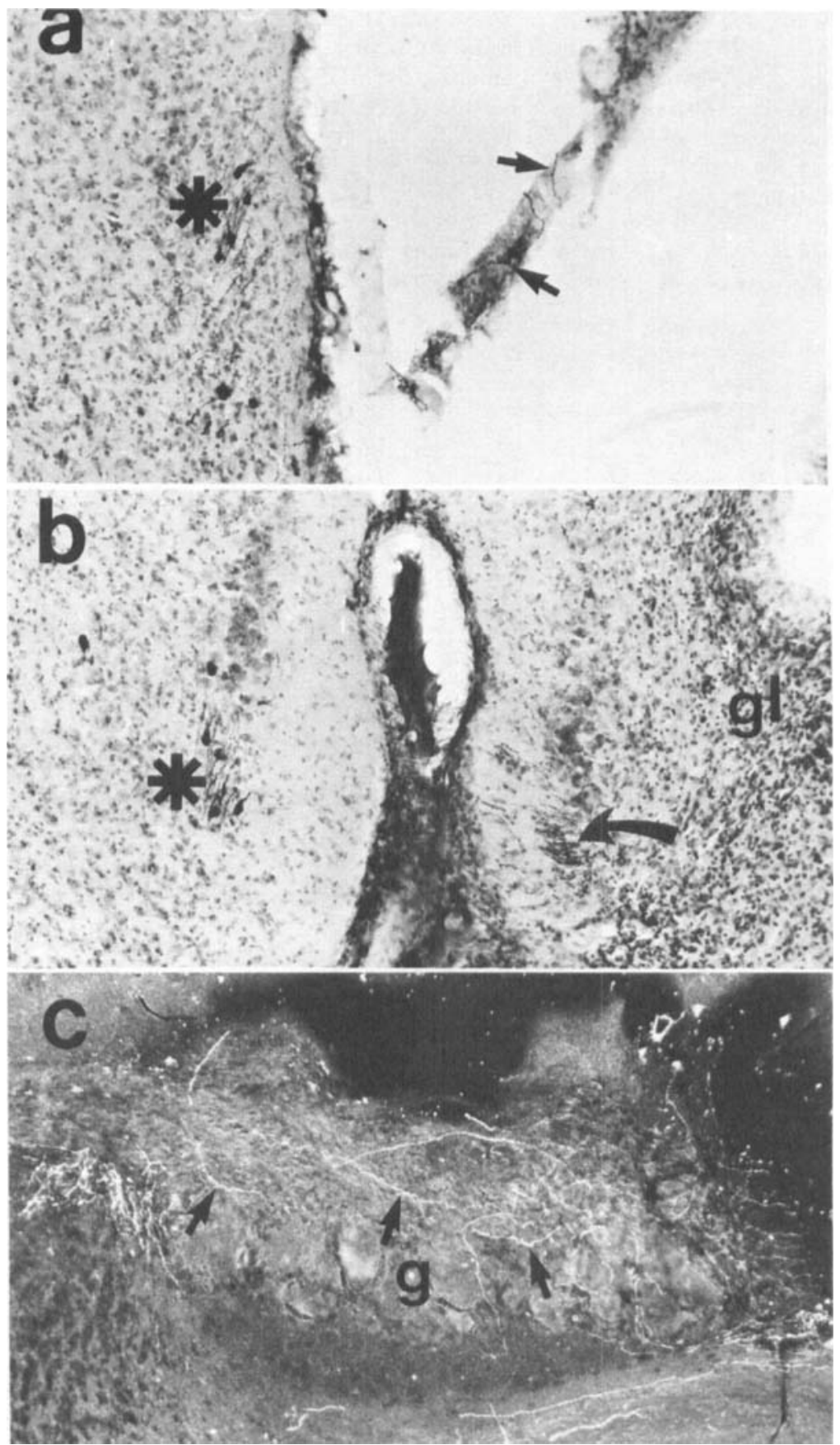


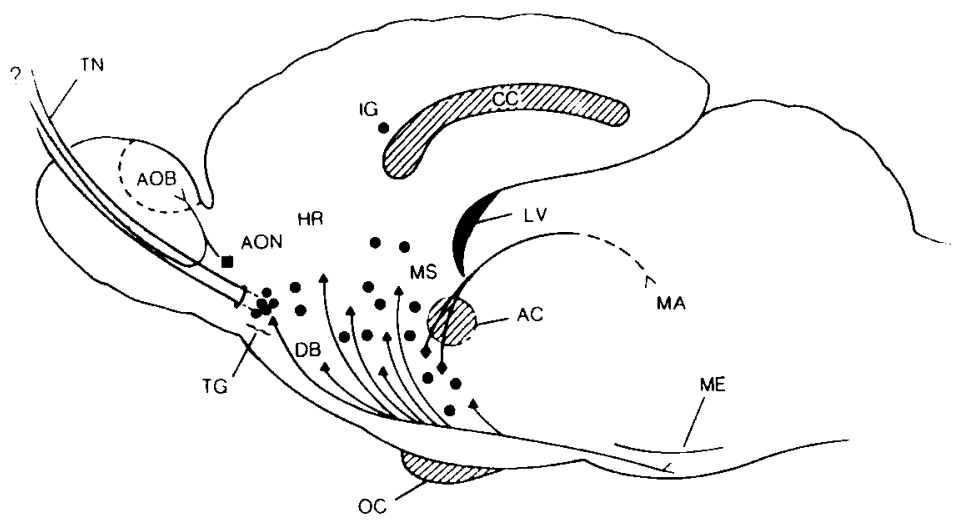

FIGURE 8. Schematic parasagittal section through a hamster brain illustrating the location of intracerebral LHRH cells (solid circles), including those which project to the accessory olfactory bulb (square), the medial nucleus of the amygdala (diamonds), and the median eminence (triangles). The possibility of projections from LHRH cells in the peripheral portion of the terminal nerve (TN) to the accessory olfactory bulb is indicated by the question mark. IG, indusium griseum; CC, corpus callosum; LV, lateral ventricle; MA, medial nucleus of the amygdala. All other abbreviations are the same as those in Figure 3.

In contrast to the small number of retrogradely labeled LHRH cells following $\mathrm{AOB}$ or $\mathrm{M}$ injections, $\mathrm{ME}$ injections consistently labeled greater numbers of LHRH cells. As in the rat ${ }^{22}$ and mouse, ${ }^{33}$ LHRH cells projecting to the ME in the hamster are not localized to any specific brain region but scattered among other LHRH cells which apparently do not project to the ME. Given our use of unilateral injections, we cannot exclude the possibility that all LHRH neurons project to some portion of the ME. However, the present results suggest that in the hamster, as in other species, LHRH cells are heterogeneous with respect to their individual projections.

Furthermore, we were surprised to find a small number of LHRH cells associated with the intracerebral portion of the terminal nerve and adjacent anterior hippocampal rudiment which were labeled after ME and LS injections. These cells were not labeled after injections into the AOB which spread into the pia-arachnoid space. Although these cells were not reported by earlier studies of afferents to the $\mathrm{ME}^{29}$ the sparse number of cells labeled may have escaped detection. LHRH cells in the terminal ganglion have been demonstrated to have access to fenestrated capillaries, ${ }^{33}$ although it is not clear whether this access is by way of projections to the $\mathrm{ME}$, or to other neurohemal regions. If cells of the intracerebral terminal ganglion do indeed project to the $\mathrm{ME}$, then an anatomic basis for terminal nerve regulation of gonadotropin secretion may exist.

FIGURE 7. Photomicrographs showing the presence of LHRH fibers in the accessory olfactory bulb following a unilateral lesion of the intracerebral portion of the terminal ganglion. (a) Coronal section through an electrolytic lesion which destroyed the left terminal ganglion but left the right terminal ganglion intact (asterisk). Note that some LHRH fibers in the pial layer of the left side of the brain remained intact (arrows). Magnification $\times 63$. (b) Section immediately rostral to (a) in which fiber bundles of the terminal nerve are apparent (arrows) adjacent to the gliotic tissue (gl) surrounding the lesion. Magnification $\times 63$. (c) Darkfield photomicrograph of the AOB on the side of the lesion. Note the presence of immunoreactive LHRH fibers (arrows) which ramify in the glomerular layer $(\mathrm{g})$. Magnification $\times 63$. 


\section{ACKNOWLEDGMENTS}

We gratefully acknowledge the technical assistance of Ms. Joni Vest, Mrs. Ying

Tsai and Mr. Anthony Kincaid, and the critical comments of Dr. Michael Shipley.

\section{REFERENCES}

1. Scalia, F. \& S. S. Winans. 1975. J. Comp. Neurol. 161 (1): 31-56.

2. WySOCKI, C. J. 1979. Neurosci. Behav. Rev. 3: 301-341.

3. Lloyd-Thomas, A. \& E. B. Keverne. 1982. Neuroscience 7 (4): 907-913.

4. Beltramino, C. \& S. TAleisnik. Neuroendocrinology 36: 53-58.

5. Coquelin, A., A. N. Clancy, F. Macrides, E. P. Noble \& R. A. Gorski. 1984. J. Neurosci. 4 (9): 2230-2236.

6. Powers, J. B. \& S. S. Winans. 1975. Science 187: 961-963.

7. Bean, N. J. 1982. Physiol. Behav. 29: 433-437.

8. Fleming, A., F. Vaccarino, L. Tambosso \& P. Chee. 1979. Science 203: 372-374.

9. Davis, B. J., F. Macrides, W. M. Youngs, S. P. Scheider \& D. L. Rosene. 1978. Brain Res. Bull. 3: 59-72.

10. Lehman, M. N., S. S. Winans \& J. B. Powers. 1980. Science 210: 557-560.

11. Beltramino, C. \& S. Taleisnik. 1978. Brain Res. 144: 95-107.

12. Witkin, J. W. \& A. J. Silverman. 1983. J. Comp. Neurol. 218: 426-432.

13. Jennes, L. \& W. E. StumpF. 1980. Cell Tissue. Res. 209: 239-256.

14. Phillips, H. S., G. Hostetter, B. Kerdelhue \& G. P. Kǒzlowski. 1980. Brain Res. 193: 574-579.

15. WirSiG, C. R. \& C. M. LeONARD. 1986. Neuroscience 19 (3):719-740.

16. Schwanzel-Fukuda, M. \& A. J. Silverman. 1980. J. Comp. Neurol. 191: 213-225.

17. Phillips, H. S., B. T. Ho \& J. G. LinNer. 1982. Brain Res. 246: 193-204.

18. Dluzen, D. E., V. D. Ramirez, C. S. Carter \& L. L. Getz. Science 212: 573-575.

19. Witkin, J. W., C. M. Paden \& A. J. Silverman. 1982. Neuroendocrinology 35: 429-438.

20. Silverman, A. J. \& L. C. KRey. 1978. Brain Res. 157: 233-246.

21. Lehman, M. N., A. J. Silverman, J. E. Robinson \& F. J. Karsch. 1986. J. Comp. Neurol. 244: 19-35.

22. Silverman, A. J., J. Jhamandas \& L. Renaud. 1987. J. Neurosci. 7: 2312-2319.

23. WIRSIG, C. R. \& C. M. LeONARD. 1986. Neuroscience 19 (3): 709-717.

24. Johnston, J. B. 1913. J. Comp. Neurol. 23: 97-120.

25. LARSELL, O. 1918. J. Comp. Neurol. 30: 3-68.

26. SchmUed, L. C. \& J. H. Fallon. 1986. Brain Res. 377: 147-154.

27. Katz, L. C., A. Burkhatter \& W. J. Dreyer. 1984. Nature 310: 498-500.

28. Silverman, A. J., J. L. Antunes, G. M. Agrams, G. Nilaver, R. Thau, J. A. RobINSON, M. Ferin \& L. C. KREY. 1982. J. Comp. Neurol. 211: 309-317.

29. Weigand, S. J. \& J. L. Price. 1980. J. Comp. Neurol. 192: 1-19.

30. De Olmos, J. H. Hardy \& L. Heimer. 1978. J. Comp. Neurol. 181: 312-344.

31. OTtersen, O. P. 1980. J. Comp. Neurol. 194 (1): 267-289.

32. Swanson, L. W. \& W. M. Cowan. 1979. J. Comp. Neurol. 186: 621-656.

33. JenNes, L. \& W. E. STUMPF. 1986. Neuroscience 18 (2): 403-416. 